\title{
Clinical Features and Lymphocyte Immunophenotyping Analysis in Primary Immunodeficiency Patients With Non-transplant Lymphoproliferative Disorders
}

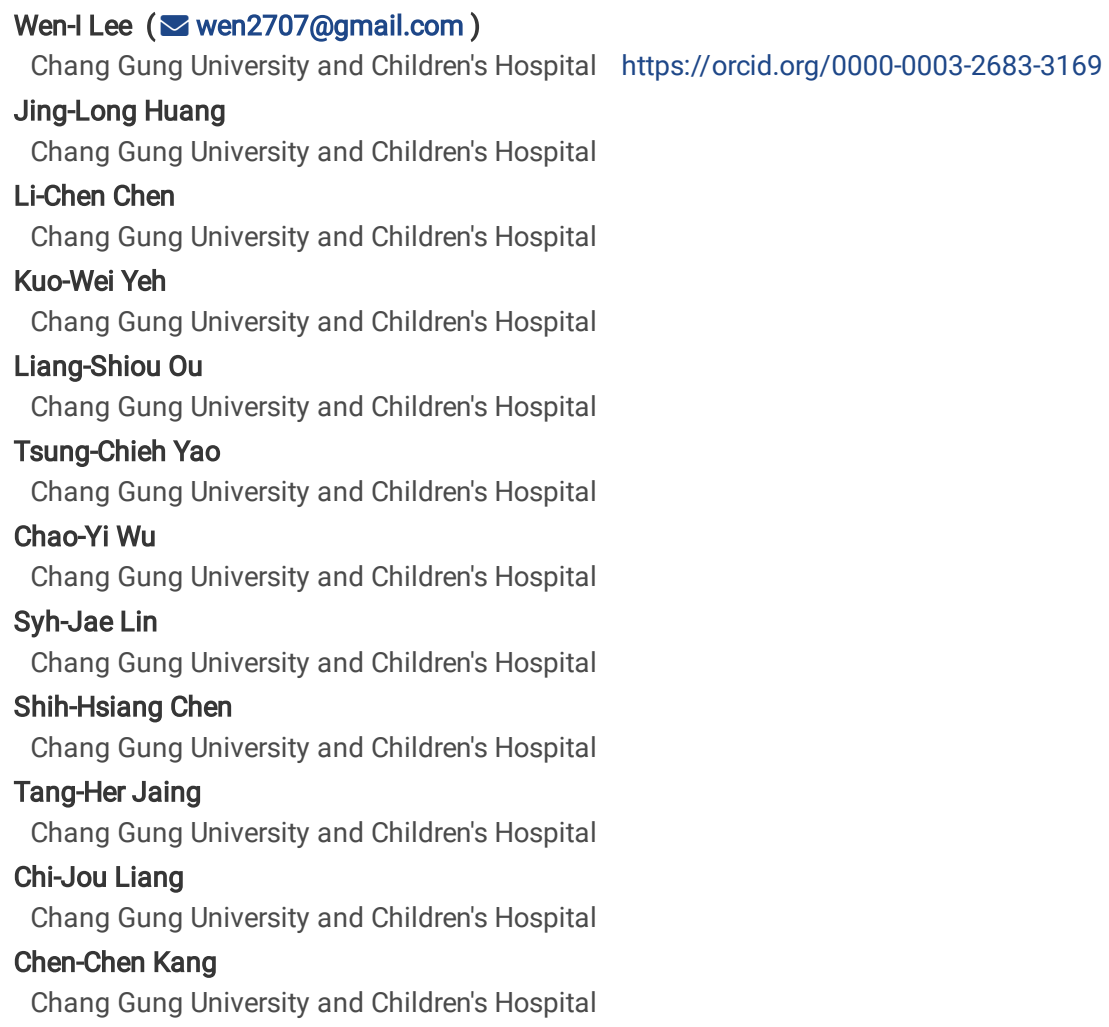

\section{Research Article}

Keywords: lymphoproliferative disorders (LPD), immunophenotyping, primary immunodeficiency diseases (PID), senescent T, CD21-low, transitional B, plasamablast B, memory cells

Posted Date: December 1st, 2021

DOl: https://doi.org/10.21203/rs.3.rs-1063277/v1

License: (9) (7) This work is licensed under a Creative Commons Attribution 4.0 International License. Read Full License 


\section{Abstract}

Purpose: Lymphoproliferative disorders (LPD) comprise a heterogeneous group of diseases and can be classified categorized into the category as being immune dysregulation diseases in primary immunodeficiency diseases (PID) that typically represent as monogenetic X-linked and autoimmune lymphoproliferative diseases (XLP and ALPS). The LPD phenotype extends to other categories in PID and its distribution remains scarce.

Methods: The clinical course and lymphocyte immunophenotyping in PID patients with the LPD phenotype who were referred to the PICAR (Primary Immunodeficiency Care And Research) institute were investigated between 2004 and 2020.

Results: Of the 96 enrolled patients, 31 (32.3\%) (median age 144, range 3-252 months) developed the LPD phenotype mainly encompassing lymphadenopathy (in 10 patients), refractory inflammatory bowel disease (IBD)-like with intestinal lymphadenopathy in 8 and hepatosplenomegaly (in 7) during long-term follow-up (median 144, range 3-252 months). The LPD phenotype was most frequently present in the categories of antibody deficiency (in 7: 2 CVID, 2 TTC37, PIK3CD, PIK3R1 and AICDA each), phagocyte (in 6: 4 CYBB, 1 STAT1 and 1 IFNRG1), immune dysregulation (in 6: 2 FOXP3, 2 XIAP and 2 HLH), combined immunodeficiencies (in 5: 2 IL2RG, 1 CD40L, 1 ZAP70 and 1 unknown) and syndromic features (in 4: 2 STAT3-LOF, 1 WAS and 1 ATM) as well as three patients with anti-IFN- $\gamma$ autoantibodies. Those with the LPD phenotype had a significantly higher mortality rate than those without $(p=0.0016)$ despite a similar age at onset (median 66 vs 44 months) and follow-up duration (138 vs 144 months). EBV virus load was only detectable in the PIK3CD and HLH patient each. An increased senescent (CD8+CD57+) and CD21-low components, and disturbed transitional B (CD38+lgM++), plasamablast B (CD38++lgM-), memory B (CD19+CD27+) and $\mathrm{T}_{\text {EMRA }}$ (CD27-lgD-) components were often observed in cross-sectional immunophenotyping. However, except patients with CD40L and ZAP70 mutations, those with profound T cell defects who bear almost naïve (T and B cells) components and extreme low in the remaining subsets components trended to develop their LPD phenotype.

Conclusion: The spectrum of the LPD phenotype in one third of the PID patients overriding the categorical boundaries had higher mortality and heterogeneous lymphocyte disturbances, especially higher senescent and CD21-low but lower memory B subpopulations. Large-scale longitudinal studies of PID patients are needed to validate the correlation between immunophenotype and the LPD status.

\section{Introduction}

Lymphoproliferative disorders (LPD) comprise a heterogeneous group of diseases characterized by the uncontrolled production of lymphocytes that mainly cause monoclonal lymphocytosis, lymphadenopathy and bone marrow infiltration [1, 2]. Patients with genetic mutations responsible for primary immunodeficiency diseases (PID) or inborn errors of immunity (IEI) can present with "combination" phenotypes of refractory allergy, recurrent infections, autoimmune, autoinflammation and malignant transformation [3]. These latter three disorders mainly underlie immune imbalance and dysregulation with the potential to increase susceptibility to the development of the LPD phenotype.

In the update PID/IEl classification, patients classified into the "immune dysregulation" category nomenclaturally bear the LPD phenotype [4]. Among them, Xlinked lymphoproliferative disease 1 (XLP1) patients with SH2D1A (SH2 domain 1A) or SAP (SLAM-associated protein) genetic mutations have been shown to be predisposed to acquire chronic and persistent EBV infection behaving as natural killer/T cell LPD overlapping recurrent infectious mononucleosis, hemophagocytic lymphohistiocytosis (HLH) and chronic active EBV infection (CAEBV), and to be at risk of the further development of lymphoma [5]. Resembling XLP1 patients, the XLP2 phenotype caused by XIAP (inhibitor of apoptosis, X-linked) mutations is recognized by huge splenomegaly and refractory inflammatory bowel disease (IBD)-like diarrhea [6]. In addition, mutations in the genes encoding Fas or associated proteins cause autoimmune lymphoproliferative syndrome (ALPS) that cannot adequately modulate apoptosis to prevent autoinflammation [7]. Beyond the "immune dysregulation" category encompassing the so-called typical LPD disorders, those patients with common variable immunodeficiency (CVID), immunodeficiency, polyendocrinopathy, enteropathy and X-linked (IPEX) or IPEX-like, severe combined immunodeficiency (SCID or CID), Wiskott-Aldrich syndrome (WAS), ataxiatelangiectasia (ATM) or Chediak-Higashi syndrome could have the potential to develop the LPD phenotype, especially in accompanying with EBV infection [8, 9].

To overview the LPD phenotype based on the update European Society for Immunodeficiencies (ESID) [10], we defined the LPD phenotype as encompassing hepatosplenomegaly, lymphadenopathy, pulmonary granuloma, intestinal lymphadenopathy, hemophagocytic lymphohistiocytosis (HLH), and lymphoma transformation. The LPD phenotype may orchestrate or interact with an imbalance in T regulatory cells (Treg), Th17 cells, T follicular help cells and others [11]. In this study, we assessed the distribution of the LPD phenotype in a cohort of patients using the updated categories and investigated whether lymphocyte disturbance may be associated with this phenotype and whether it can affect the prognosis.

\section{Material And Methods}

\section{Patients}

Since 2003, 1220 individuals (838 suspected cases and 382 related persons) have been referred to the Primary Immunodeficiency Care and Research (PICAR) Institute for molecular/genetic diagnosis of PID. Two hundred and eighty patients were identified as having PID (Supplemental Fig. 1) and were classified according to the 2019 updated PID categories [4], as in our previous study [15]. The patients and healthy controls provided informed and written consent for data collection and publication of this study. All human samples were obtained under protocols approved by the Institutional Review Board at Chang Gung Memorial Hospital (protocol 202001665A3, 202002403A3, and 201902037A3) and met the Institutional Review Board standards for ethical conduct of research with human subjects. Written informed consent was obtained from all individual participants included in the study. Basic immunologic functions were assessed according to clinical characteristics and candidate genes were sequenced from complement DNA synthesized from RNA and confirmed again

Page 2/16 
using genomic DNA as previously described. [12-14] For those with the LPD phenotype [7, 8, 10], we investigated their clinical features, lymphocyte imbalance and categorial distribution.

\section{Assessment of memory, T follicular helper, senescent, Th17, Treg, transitional and plasmablast B cells}

Peripheral blood mononuclear cells (PBMCs) were processed using Ficoll (GE Healthcare, Marlborough, MA, USA) to form a single cell suspension, which was then stained with the following monoclonal antibodies against cell surface and intracellular antigens of memory $T$, Treg, $T$ follicular helper, memory $B$, and CD21-low B cells as in our previous study [12, 16]: anti-CD4-PE (clone SK3), CD4 FITC (clone SK3), CD8-PE (clone SK1), CD19-PerCP-Cy5.5 (clone HIB19), CD25-FITC (clone 2A3), CD21-FITC (clone B-ly4), IgD-PE (clone IA6-2), CD27-APC (clone M-/t271), CD45RO-PE (clone UCHL1), CD154-PE (clone TRAP1), CCR7APC (CD197, clone 3D12), CXCR5 PerCP-Cy5.5 (clone RF8B2), CD38-PE (colon HIT2), IgM-FITA (clone FA-DA4), CD57-PE (colon TB01), IgD-PE (clone IA6-2) (all from BD Pharmingen and eBioscience, San Diego, CA).

\section{Statistical analysis}

The phenotypes, treatment, and prognosis of our patients with and without LPD were compared. The first follow-up day was defined as the age at onset, and the last follow-up day was the near recent clinical visit. The survival analysis, t-test and chi-square were performed using GraphPad Prism software, and a $p$ value of $<0.05$ was considered to indicate a statistically significant difference.

\section{Results}

\section{The Distribution Of Lpd In The Update Categories}

Among 280 recognized patients at our PICAR institute, 96 had long-term follow-up (mean 130, median 144, range, 3-252 months) in our institute. The autoimmune-related disorders in our cohort [15] included severe atopic dermatitis, herpes-like dermatitis, idiopathic thrombocytic purpura, alopecia, Takayasu's vasculitis, albinism and the LPD phenotype. A total of 31 patients had the LPD-related phenotype, including lymphadenopathy (in 10 patients), hepatosplenomegaly (in 7), refractory diarrhea (IBD-like with intestinal lymphadenopathy in 7), granuloma (lung and skin in 3), hemophagocytic lymphohistiocytosis (HLH in 3), lymphoma (in 2), and splenomegaly (in 1) (Table 1). The LPD phenotype was most present in the antibody deficiency (7 of 19 patients), phagocyte (6 of 19), and immune dysregulation (6 of 6 ) categories.

Table 1

The lymphoproliferative disorder (LPD) phenotypes in the PID patients classified by every category

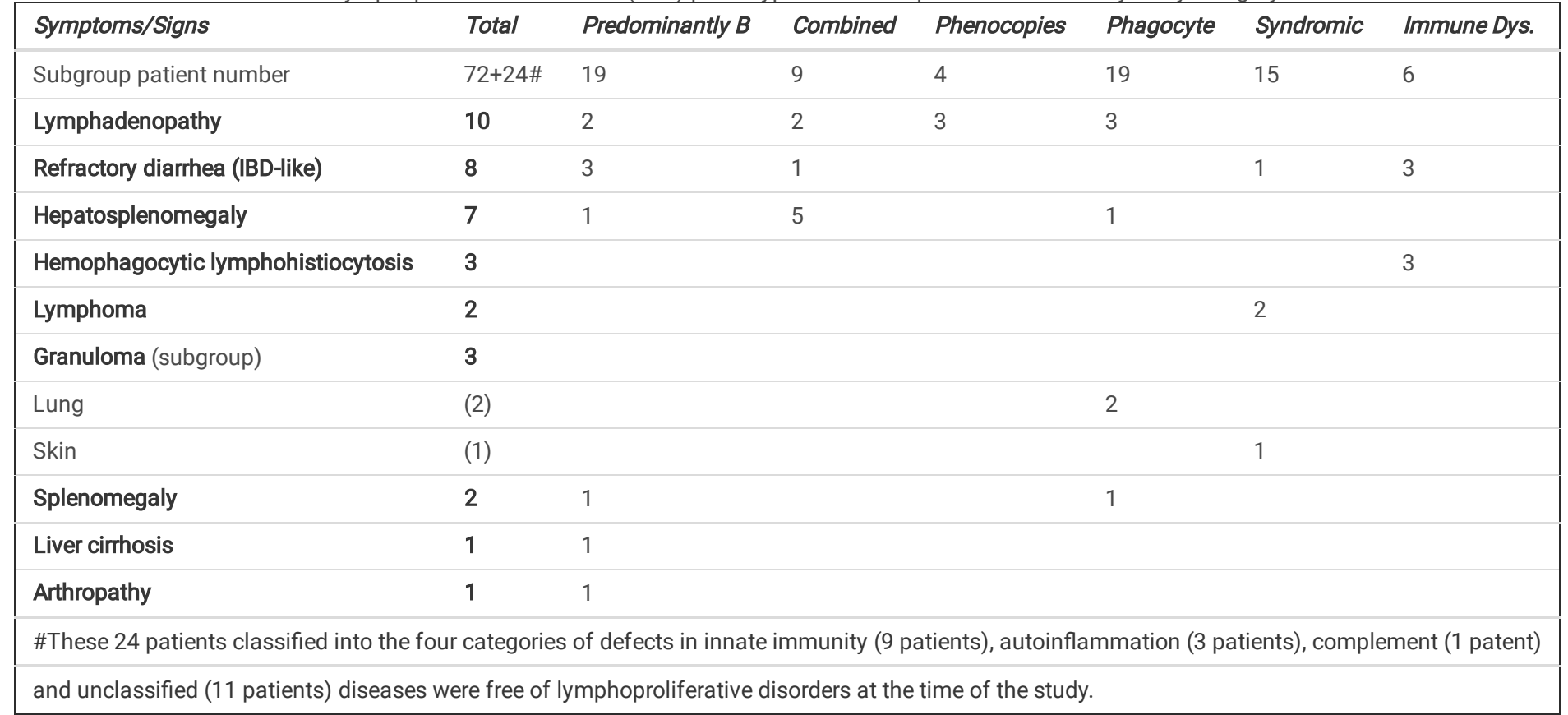

The diagnosis of ALPS was excluded by normal TCRa- $\beta$ - subsets, absent autoimmune pancytopenia and all wild-type genetic analysis in the Fas or associated proteins, confirmed by whole exome sequencing.

The most common genetic defect was CYBB (4 patients), followed by TTC37, IL2RG, STAT3-LOF, XIAP and FOXP3 in two patients each, and PIK3CD, PIK3R1, CD40L, ZAP70, STAT1, IFNRG1, WAS and ATM in one patient each (Table 2). The genetic defects of three patients with anti-IFN-y autoantibodies, two patients with CVID, two with $\mathrm{HLH}$, and one with CID could not be identified. 
Table 2

Lymphoproliferative disorders and opportunistic infections in non-transplant PID patients

\begin{tabular}{|c|c|c|c|c|c|c|c|c|}
\hline \multirow{3}{*}{$\begin{array}{l}\text { Patient } \\
\text { / sex }\end{array}$} & \multirow{3}{*}{$\begin{array}{l}\text { Tested } \\
\text { age } \\
\text { (Months) }\end{array}$} & \multirow{3}{*}{$\begin{array}{l}\text { Mutations or/ } \\
\text { clinical diagnosis }\end{array}$} & \multicolumn{6}{|c|}{ Clinical presentation } \\
\hline & & & \multirow{2}{*}{$\begin{array}{l}\text { Opportunistic } \\
\text { infection }\end{array}$} & \multicolumn{5}{|c|}{ Autoimmune/Inflammation disorder } \\
\hline & & & & Lymphadenopathy & Hepatosplenomegaly & $\begin{array}{l}\text { IBD-like } \\
\text { diarrhea }\end{array}$ & Others & $\begin{array}{l}\text { Basic } \\
\text { Treatment } \\
\text { [mortality] }\end{array}$ \\
\hline \multicolumn{9}{|c|}{ Predominantly antibody deficiencies (19) } \\
\hline $\begin{array}{l}\text { P52 / } \\
\text { M }\end{array}$ & 273 & Undefined/CVID & & & + & & & $\begin{array}{l}\text { [IVIG, } \\
\text { prednisolone] }\end{array}$ \\
\hline $\begin{array}{l}\text { P71 / } \\
\text { F }\end{array}$ & 744 & Undefined/CVID & & + & & & & IVIG \\
\hline $\begin{array}{l}\text { P429 / } \\
\text { F }\end{array}$ & 5 & $\begin{array}{l}\text { TTC37, } 3724 \text { ins A, } \\
\text { Tyr1169Stop }\end{array}$ & & & & + & Liver cirrhosis & $\begin{array}{l}\text { IVIG, } \\
\text { prednisolone }\end{array}$ \\
\hline $\begin{array}{l}\mathrm{P} 321^{*} \\
/ \mathrm{M}\end{array}$ & NB & $\begin{array}{l}\text { TTC37, } \\
\text { homozygous } \\
\text { DelK1155H, Fs*2; }\end{array}$ & & & & + & & $\begin{array}{l}\text { [IVIG, } \\
\text { prednisolone] }\end{array}$ \\
\hline \multirow[t]{2}{*}{$\begin{array}{l}\text { P622 / } \\
\text { F }\end{array}$} & 11 & $\begin{array}{l}\text { PIK3CD, c. } 3061 \mathrm{G}>\mathrm{A} ; \\
\text { p. E. } 1021 \mathrm{~K}\end{array}$ & EBV, CMV & & & + & & $\begin{array}{l}\text { IVIG, } \\
\text { prednisolone, } \\
\text { mTOR, }\end{array}$ \\
\hline & & & & & & & & HSCT \\
\hline \multirow[t]{2}{*}{$\begin{array}{l}\mathrm{P} 728 \text { / } \\
\mathrm{M}\end{array}$} & 208 & $\begin{array}{l}\text { PIK3R1, } \\
\text { c. } 1425+2 T>G\end{array}$ & & + & & & Arthropathy & $\begin{array}{l}\text { IVIG, } \\
\text { prednisolone, } \\
\text { mTOR, }\end{array}$ \\
\hline & & & & & & & & $\begin{array}{l}\text { anti-TNF, anti- } \\
\text { IL6 }\end{array}$ \\
\hline \multirow{2}{*}{$\begin{array}{l}\text { P323 / } \\
\text { F }\end{array}$} & 20 & AICDA, & & & & & Splenomegaly & IVIG \\
\hline & & Del 37Asp38Ser & & & & & & \\
\hline \multicolumn{9}{|c|}{ Combined T and B immunodeficiencies (9) } \\
\hline $\mathrm{P9} / \mathrm{M}$ & 10 & IL2RG, Trp74Gly & $\begin{array}{l}\text { Oral } \\
\text { candidiasis, } \\
\text { PJP }\end{array}$ & & + & & erythroderma & IVIG, HSCT \\
\hline $\begin{array}{l}\text { P394 / } \\
\text { M }\end{array}$ & 3 & $\begin{array}{l}\text { IL2RG, c. } 854 G>A \text {, } \\
\text { skip exon } 6\end{array}$ & $\begin{array}{l}\text { Oral } \\
\text { candidiasis, } \\
\text { PJP }\end{array}$ & & + & & & [IVIG] \\
\hline $\begin{array}{l}\text { P325 } \\
\text { /M }\end{array}$ & 1 & Undefined/CID & $\begin{array}{l}\text { BCG, } \\
\text { candidiasis }\end{array}$ & + & + & & & IVIG, HSCT \\
\hline $\begin{array}{l}\mathrm{P} 72 / \\
\mathrm{M}\end{array}$ & 121 & CD40L, Del 347A & $\begin{array}{l}\text { Oral } \\
\text { candidiasis, }\end{array}$ & + & + & & & IVIG \\
\hline $\begin{array}{l}\text { P635 / } \\
\text { M }\end{array}$ & 22 & $\begin{array}{l}\text { ZAP70. c.1561 G>A; } \\
\text { Asp } 521 \text { Asn }\end{array}$ & $\begin{array}{l}\text { Oral } \\
\text { candidiasis, } \\
\text { PJP }\end{array}$ & & + & + & hepatitis & $\begin{array}{l}\text { IVIG, } \\
\text { prednisolone, } \\
\text { HSCT }\end{array}$ \\
\hline \multicolumn{9}{|c|}{ Phenocopies of PID (Auto IFN-ץ Abs) (4) } \\
\hline $\begin{array}{l}\text { P32 / } \\
\text { F }\end{array}$ & 613 & $\begin{array}{l}\text { Undefined/recurrent } \\
\text { NTM }\end{array}$ & $\begin{array}{l}\text { NTM, } \\
\text { varicella, } \\
\text { Talaromyces } \\
\text { (Penicillium) } \\
\text { marneffei }\end{array}$ & + & & & & $\begin{array}{l}\text { Anti-NTM, } \\
\text { prednisolone }\end{array}$ \\
\hline $\begin{array}{l}\text { P188 / } \\
\text { F }\end{array}$ & 624 & $\begin{array}{l}\text { Undefined/recurrent } \\
\text { NTM }\end{array}$ & NTM & + & & & & Anti-NTM \\
\hline $\begin{array}{l}\text { P197 / } \\
\text { M }\end{array}$ & 675 & $\begin{array}{l}\text { Undefined/recurrent } \\
\text { NTM }\end{array}$ & NTM & + & & & & $\begin{array}{l}\text { Anti-NTM, } \\
\text { prednisolone }\end{array}$ \\
\hline \multicolumn{9}{|c|}{ Congenital defects of phagocyte number, function or both (19) } \\
\hline $\begin{array}{l}\text { P54 / } \\
\text { M }\end{array}$ & 66 & STAT1, Thr385Met & $\begin{array}{l}\text { BCG, } \\
\text { candidiasis }\end{array}$ & + & + & & Hypothyroidism & $\begin{array}{l}\text { IVIG, } \\
\text { prednisolone, } \\
\text { HSCT }\end{array}$ \\
\hline
\end{tabular}

Abbreviations: CVID: common variable immunodeficiency, IBD: inflammatory bowel disease; HLH: hemophagocytic lympho-histiocytosis; NTM: nontuberculosis mycobacterial infections; WAS: Wiskott-Aldrich syndrome; ATM: ataxia-telangiectasis; There were no lymphoproliferation syndrome in the categories of Autoinflammatory disorders and defects in innate immunity 


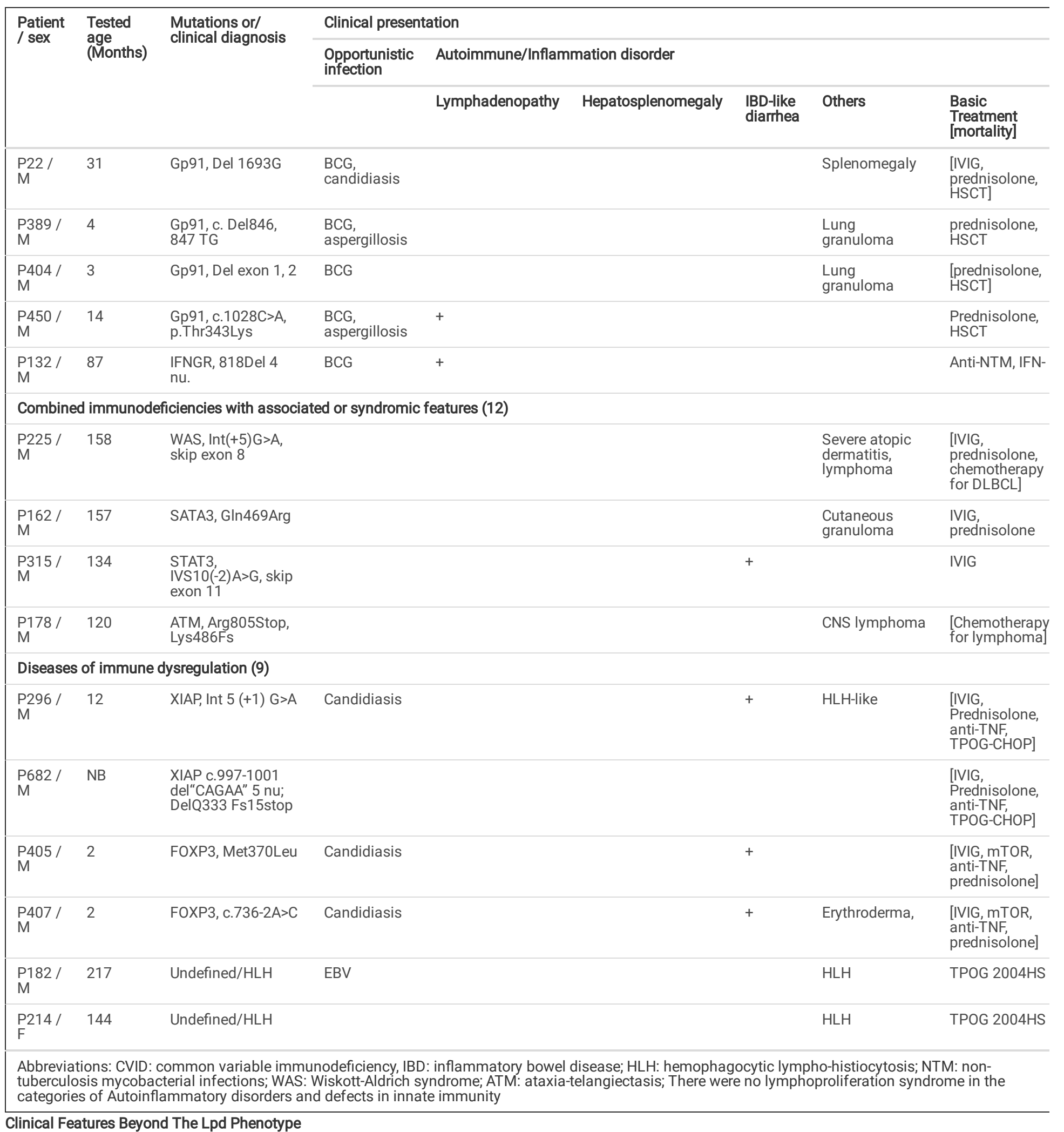

As expected, patients with combined T and B cell deficiency (caused by IL2RG, ZAP70 and CD40L mutations), defective phagocyte reactive oxygen species (caused by CYBB mutations) and IFN-Y/IL12/23 dysfunction (due to autoantibodies to IFN-Y and STAT1 mutations) often suffered from opportunistic infections, such as mucosa candidiasis, nontuberculosis mycobacteria infections, aspergillosis, varicella and Talaromyces (Penicillum) marneffei. Only two patients with PIK3CD (P622) and an unknown genetic defect (P182) had a detectable EBV or/and CMV viral load in all 31 patients. Two patients with WAS and ATM did not have detectable viral load, however they both developed lymphoma.

Compared to the PID patients without the LPD phenotype, those with the LPD phenotype had a significantly higher mortality rate ( $p=0.0061$, log-rank test; $p=0.0124$, Wilcoxon test; Fig. 1A) during a similar follow-up period (median 138 vs 144 months, range 4-252 months vs 3-212 months, $p=0.3470$; Fig. 1B) even though there was no significance in the age at recognition (median 66, range 0.003 to 675 months; vs median 40 , range 1 to 972 months, p=0.3672; Fig. 1C). The age at onset of the LPD phenotype was not significantly different between the survivors and the mortalities (median 81 , range 1 to 675 months; vs median 
5, range 0.03 to 273 months, $p=0.1730$; Fig. 1D), although the survivors tended to have an older age at onset of the LPD phenotype. Among the PID patients with the LPD phenotype, the prognostic factors for survival were not correlated to opportunistic infections, hepatosplenomegaly, and IBD-like diarrhea (chisquare test; Supplemental Table 1). Notably, the presence of lymphadenopathy seemed to be an independent survival factor, because the 10 patients with lymphadenopathy all survived.

All patients had bronchiectasis except for three who received early effective IVIG (P 323) hematopoietic stem cell transplantation (HSCT) (P450) and prophylactics (P134). The treatments affecting nature courses of the LPD phenotype mainly included regular IVIG (in 21), immunosuppressants (prednisolone in 19 patients), mTOR inhibitors (rapamycin in 2), biologics (in 2), chemotherapy based on the TPOG (Taiwan Pediatric Oncologic Group) guideline (in 4), and HSCT (in 9) if their courses were refractory and suitable donors were available to rescue them from the LPD phenotype, including IBD-like diarrhea, erythroderma, autoimmune hepatitis and lung granuloma.

\section{Lymphocyte disturbance in the PID patients with the LPD phenotype}

Among the PID patients with the LPD phenotype, immunophenotyping in the "predominantly antibody deficiencies" category showed decreased memory B but higher CD4+ effector memory T and CD21-low B cell components (in Table 3), and especially higher Tfh and senescent components in the patients with PIK3CD and PI3K3R1 mutations (as shown in P728 in Fig. 2). All patients in the "combined T and B immunodeficiency" category had fewer memory cells.

Extremely low numbers of T cells with an almost naïve pattern were common in three patients with IL2RG (P9 and P394) and undefined (P325) mutations, but not in two patients with respective CD40L and ZAP70 mutations (P72 and P635) whose T (CD4+ and CD8+) and B (CD19+) cell components were normal and senescent cell components were higher. 
Table 3

Lymphocyte subpopulation percentages in the PID patients with the lymphoprolifera

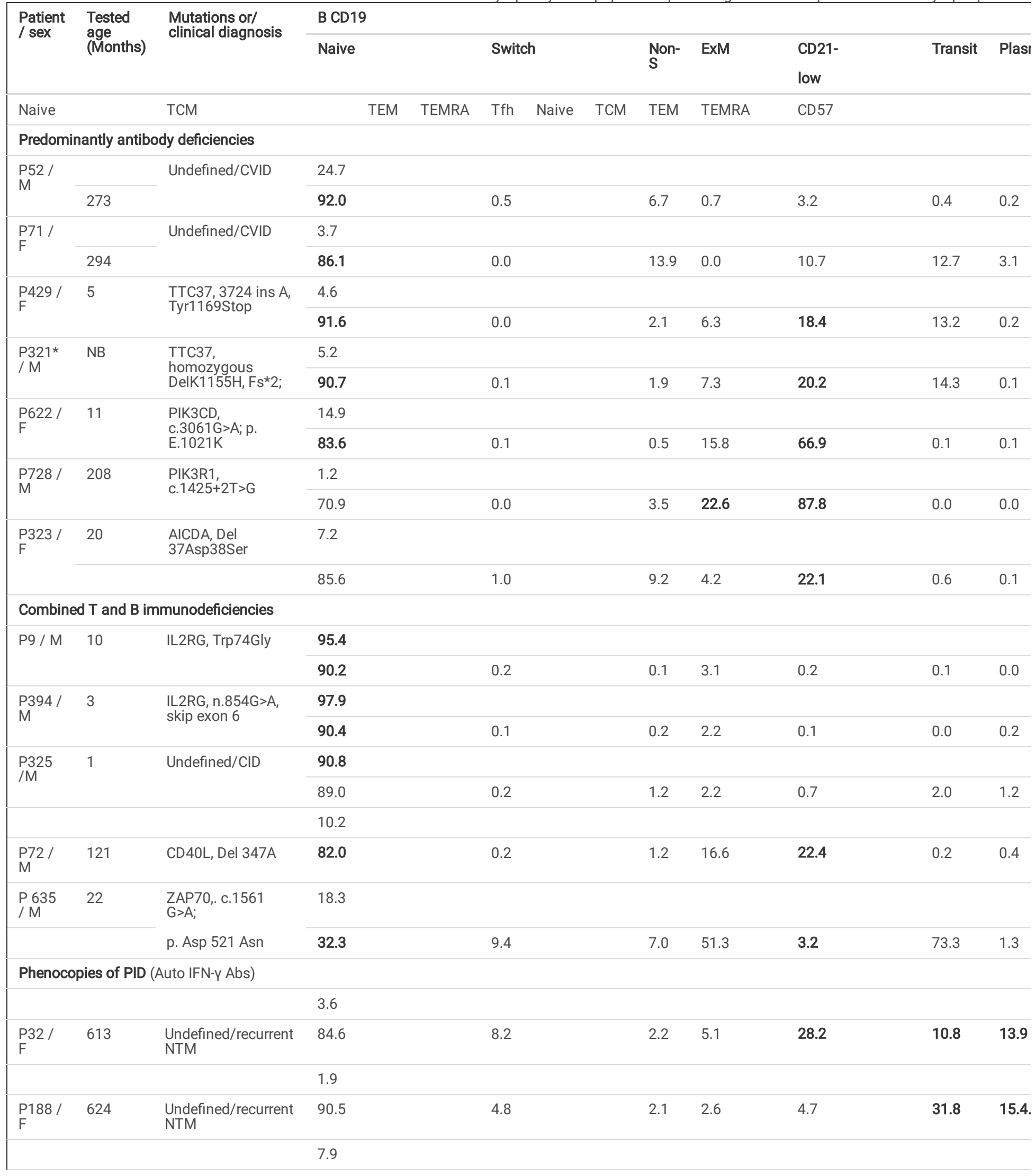

Pink background indicates higher than the normal range; Gray background indicates lower than the normal range, mainly based on our age-matched controls

^ Kverneland AH, Streitz M, Geissler E, Hutchinson J, Vogt K, Boës D, Niemann N, Pedersen AE, Schlickeiser S, Sawitzki B. Age and gender leucocytes variance Jun;89(6):543-64. doi: 10.1002/cyto.a.22855. Epub 2016 May 3. PMID: 27144459.

^^ Garcia-Prat M, Álvarez-Sierra D, Aguiló-Cucurull A, Salgado-Perandrés S, Briongos-Sebastian S, Franco-Jarava C, Martin-Nalda A, Colobran R, Montserrat I, $\mathrm{F}$ reference values in a healthy pediatric population. Cytometry B Clin Cytom. 2019 May;96(3):223-233. doi: 10.1002/cyto.b.21728. Epub 2018 Oct 17. PMID: 3C 


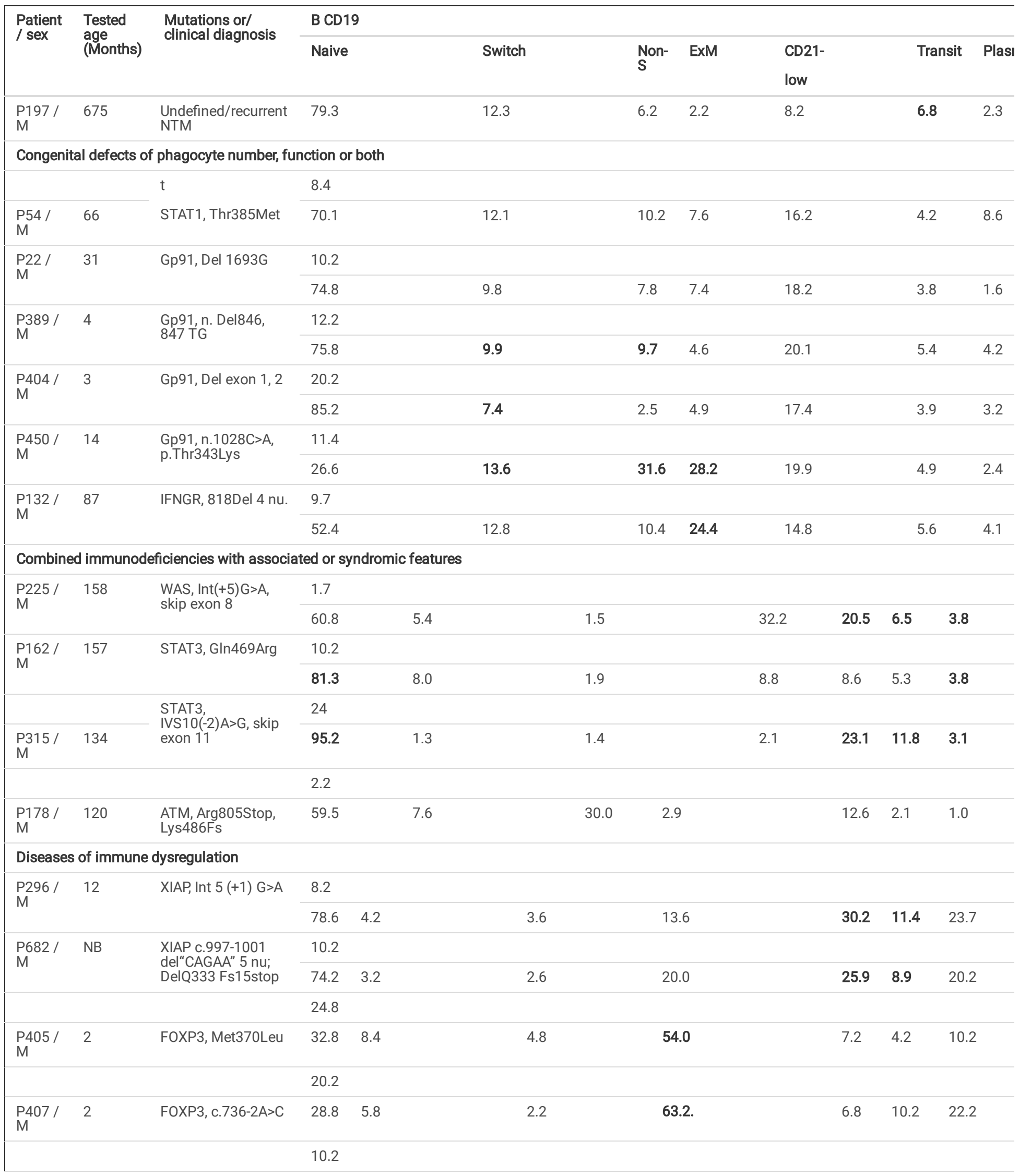

Pink background indicates higher than the normal range; Gray background indicates lower than the normal range, mainly based on our age-matched controls ^ Kverneland AH, Streitz M, Geissler E, Hutchinson J, Vogt K, Boës D, Niemann N, Pedersen AE, Schlickeiser S, Sawitzki B. Age and gender leucocytes variance Jun;89(6):543-64. doi: 10.1002/cyto.a.22855. Epub 2016 May 3. PMID: 27144459.

^^ Garcia-Prat M, Álvarez-Sierra D, Aguiló-Cucurull A, Salgado-Perandrés S, Briongos-Sebastian S, Franco-Jarava C, Martin-Nalda A, Colobran R, Montserrat I, $\mathrm{f}$ reference values in a healthy pediatric population. Cytometry B Clin Cytom. 2019 May;96(3):223-233. doi: 10.1002/cyto.b.21728. Epub 2018 Oct 17. PMID: 3C 


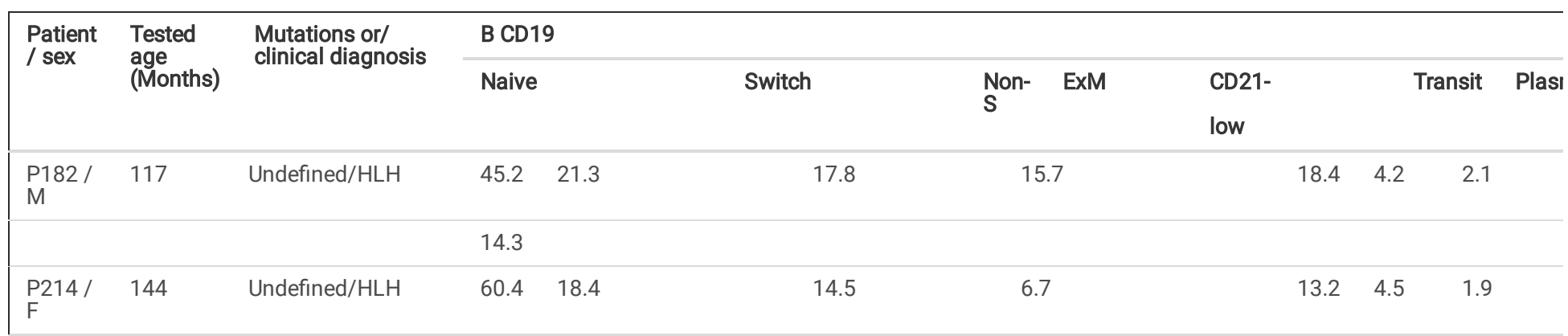

Pink background indicates higher than the normal range; Gray background indicates lower than the normal range, mainly based on our age-matched controls

^ Kverneland AH, Streitz M, Geissler E, Hutchinson J, Vogt K, Boës D, Niemann N, Pedersen AE, Schlickeiser S, Sawitzki B. Age and gender leucocytes variance Jun;89(6):543-64. doi: 10.1002/cyto.a.22855. Epub 2016 May 3. PMID: 27144459.

^^ Garcia-Prat M, Álvarez-Sierra D, Aguiló-Cucurull A, Salgado-Perandrés S, Briongos-Sebastian S, Franco-Jarava C, Martin-Nalda A, Colobran R, Montserrat I, reference values in a healthy pediatric population. Cytometry B Clin Cytom. 2019 May;96(3):223-233. doi: 10.1002/cyto.b.21728. Epub 2018 Oct 17. PMID: 3(

The patients with autoantibodies to IFN-y had higher components of transitional B, plasmablast B, effector CD4 memory, $\mathrm{T}_{\text {EMRA }}$ and senescent cells (as shown in P188 in Fig. 3). Their Th17 component was elevated to 8\% (in the second lane of Fig. 3), which was the highest in our cohort. For phagocyte disorders, the patients with X-linked granulomatous diseases (XL-CGD) had higher memory B and senescent components (representative demonstration of P450 in Fig. 4). Their Th1-polarizing Tfh components (in the third lane of Fig. 4) could elicit a robust IFN- $\gamma$ response to possibly induce a cytokine storm, consequently driving the HLH crisis.

Our syndromic PID patients with WAS, hyper IgE syndrome and ATM had decreased memory (B and T) but still higher senescent components. Two XIAP patients had higher CD21-low and transitional B components (Fig. 5A). Two IPEX patients had higher exhausted memory (IgD-lgM-, double negative cell) components (Fig. 5B).

Overall, the number of dysregulated lymphocyte subpopulations (total 22 recorded subpopulations in Table 3) was not significantly correlated with mortality. In extreme cases, a patient (P349) with 19 abnormal subpopulations and another (P22) with all normal subpopulations both died.

\section{Conclusions}

Approximate one third (31 of 96) of the PID patients presented with the LPD phenotype and higher mortality rate when compared to those without the LPD phenotype. Eleven fatal PID patients with the LPD phenotype may have been ascribed to the absence of timely HSCT, except for two with TTC37 and ATM mutations (P429 and P178), neither of whose respective liver cirrhosis and brain lymphoma benefitted from HSCT. Those patients with XIAP and FOXP3 mutations should early receive HSCT to reconstruct multiple immunophenotype disturbances [27] that theoretically contribute to recurrent HLH and refractory IBD-like diarrhea. Such lymphocyte disturbances of higher components of CD21-low B, transitional B, exhausted B and senescent T cells were not only demonstrated in the category of "immune dysregulation" as XIAP, FOXP and HLH patients, but also expanding into other categories in which the LPD phenotype could also result from an imbalance in Tfh and memory components.

In immunophenotyping analysis, higher senescent components (CD8+CD57+) with low IL-2 but pronounced IFN-y production [17, 18] were the most common. The senescent cells are telomere-dependent and low number in children but accumulate with age as seen with the TEMRA cells in patients who had anti-IFNY autoantibodies (P32, P188 and P157) and the patient with a PIK3CD mutation who persisted EBV and CMV infections (P622) presenting with hyper IgM syndrome [12,19] and PASLI (P1108-Activating mutation causing Senescent T cells, Lymphadenopathy, and Immunodeficiency) disease [20]. Higher percentages of senescent cells were noted in two patients ( $58.4 \%$ in the patient with WAS and $20.9 \%$ in the patient with ATM) who developed lymphoma in the absence of detectable EBV virus load. Whether a higher CD8+CD57+T component increases the potential for malignant transformation in PID patients with the LPD phenotype remains to be elucidated.

Through CD40L, ICOS and IL-21 signaling [21, 22], circulating Tfh cells can induce B cells to class switch and differentiate into memory and plasmablast (CD38++lgM-) cells as long-lived humoral immunity [23]. Lower Tfh cell components in those with B cell deficiency negatively affected the process of memory and plasmablast cells and consequently converged to hypogammaglobulinemia in the "predominantly antibody deficiencies" category. In contrast, the patients with PIK3CD and PIK3R1 mutations maintained higher circulating Tfh components, which could reflect that the higher number of Tfh cells in their huge hepatosplenomegaly and intestinal lymphadenopathy in situ, continuously reacted with chronic EBV or CMV infections leading to refractory IBD-like diarrhea.

In the patients with WASP, STAT3, XIAP and anti-IFNy autoantibodies, the higher transitional B component (CD38++lgM++) surviving through negative/positive selection, as well as more plasmablast (CD38++lgM-) cells, mutually produced more auto-antibodies to target intestines and blood cells presenting as the LPD phenotype of IBD-like diarrhea, lymphadenopathy and HLH.

Furthermore, $C D 21$-low B cell components belonging to CD21+CD27+ memory B cells were undetectable in cord blood and increased in autoimmune diseases [24], as all LPD patients except those with profound T cell defects (the CID patients) who simultaneously had diminished CD21-low B cell development because of defective support from T cell pool. In particular, the XL-CGD patient (P450) was like untreated rheumatoid arthritis patients with higher exhausted memory B cells (ExM, double negative IgM-lgD-) [25], in whom a cytokine storm was overwhelmingly active and therefore could induce HLHlike macrophage activation syndrome. The other four patients (P132. P405, P407, P450) in two categories of phagocyte disorders and immune dysregulation 
had also higher ExM memory B cells and increased the risk of HLH. Thus, based on such observation, further studies are warranted to investigate whether higher ExM B cell components relate to cytokine storms and therefore progress into HLH status.

Consistent with our previous study that Treg and Th17 cells remain at a lower range in most PID patients [15], relatively higher Treg populations in patients with PIK3R1, ZAP70, IFNGR and STAT3 mutations may compensate an overactive inflammation/autoimmune response during LPD status. In other words, the highest Th17 component in the patients with anti-IFNy autoantibodies inferred that Th17 augmentation positively enhanced the higher levels of anti-IFNy autoantibodies. As well as anti-CD20 deleting B-cell therapy (rituximab) to eradicate anti-IFNy autoantibodies as far as possible [26], anti-Th17 antagonists (secukinumab) may be an additional treatment to attenuate Th17 signaling for decreasing anti-IFNy autoantibodies.

This study should be interpreted in a light of its limitations. First, the cross-sectional assessments of lymphocyte immunophenotypes at diagnosis of the LPD phenotype may have been, at least partially, confounded by accompanying subclinical infections. Longitudinal and large-scale follow-up comparisons of lymphocyte immunophenotypes in patients with and without LPD should more accurately reflect the whole phenotypic spectra. Second, in addition to quantitative evaluations, functional studies of cytokine profiles (IL-10, TGF- $\beta$, and IL17), Treg contact suppression and immunoglobulin class-switch under Tfh co-culture will hopefully be assessed in future studies if more blood samples become available in pediatric-onset PID patients. Third, the CID patients with profound T cell defects had lower components of all immunophenotypes except naïve lymphocytes, which hindered clarifying the relationship between the LPD phenotype and extreme lymphocyte subpopulations including, at least, CD21-low, transitional, plasmablast B cells, Tfh, TEMRA and senescent cells. Fourth, as well as relative lymphocyte components, absolute counts might indicate the occurrence and development of the LPD phenotype if we could have obtained these two values at the same time.

In conclusion, increased senescent CD8+CD57+ and CD21-low components and disturbed transitional B, plasmablast B and TEMRA components were observed in our 31 Taiwanese PID patients with the LPD phenotype who had higher mortality. EBV infection was only detected in two (2/31), but unrelated to lymphoma transformation in the other two. However, in those with profound T cell defects rather than the CD40L and ZAP70 mutations, whether the predominantly naïve lymphocyte ( $T$ and B cell) components and extremely low in the remaining populations were correlated with their LPD phenotype remains to be determined.

\section{Declarations}

\section{Acknowledgments}

The authors wish to thank all of the patients and their families for their kind cooperation, as well as their physicians for the referrals.

Funding: Chang-Gung Medical Research Progress (Grant CMRPG 3K2231 and CMRPG3K0361), the National Science Council (Grants NSC 102-2314-B-182A039-MY3, MOST 106-2314-B-182A-147 and NMRPG3L0241 and PMRPG3H0051) and Taiwan Foundation for Rare Disorders (TFRD).

Financial Disclosure: The authors have no financial relationships relevant to this article.

Conflicts of Interest: The authors have no conflicts of interest relevant to this article.

Availability of data and material: The datasets generated during the current study are available in this article and from the corresponding author on reasonable request

Author Contributions: Lee WI, Liang CJ and Kan CC carried out the molecular genetic studies, analyzed the sequence alignment and drafted the manuscript. Lee WI and Huang JL performed the immunoassays and designed the study and the statistical analysis. Chen LC, Yeh KW, Yao TC, Ou LS, Wu CY, Lin SJ, Jaing $\mathrm{TH}$, Chen SH and Huang JL participated in the study to care for the critical patients. All authors read and approved the final version of the manuscript.

Ethics approval: All human samples were obtained under protocols approved by the Institutional Review Board at Chang Gung Memorial Hospital (protocol 202001665A3, 202002403A3, and 201902037A3) and met the Institutional Review Board standards for ethical conduct of research with human subjects.

Consent to participate: Written informed consent was obtained from all individual participants included in the study.

Consent for publication: The authors affirm that human research participants provided informed consent for publication.

\section{References}

1. Chen C, Gu YD, Geskin LJ. A Review of Primary Cutaneous CD30+ Lymphoproliferative Disorders. Hematol Oncol Clin North Am. 2019;33:121-134.

2. Sawada A, Inoue M. Hematopoietic Stem Cell Transplantation for the Treatment of Epstein-Barr Virus-Associated T- or NK-Cell Lymphoproliferative Diseases and Associated Disorders. Front Pediatr. 2018;6:334.

3. Boisson B, Quartier P, Casanova JL. Immunological loss-of-function due to genetic gain-of-function in humans: autosomal dominance of the third kind. Curr Opin Immunol. 2015 Feb;32:90-105. doi: 10.1016/j.coi.2015.01.005. Epub 2015 Jan 31. PMID: 25645939; PMCID: PMC4364384.

4. Tangye SG, Al-Herz W, Bousfiha A, Chatila T, Cunningham-Rundles C, Etzioni A, et al. Human inborn errors of immunity: 2019 update on the classification from the International Union of Immunological Societies Expert Committee. J Clin Immunol. 2020; 40:24-64.

5. Sayos J, Wu C, Morra M, Wang N, Zhang X, Allen D, et al. The X-linked lymphoproliferative-disease gene product SAP regulates signals induced through the co-receptor SLAM. Nature. 1998;395:462-9. 
6. Rigaud S, Fondanèche MC, Lambert N, Pasquier B, Mateo V, Soulas P, et al. XIAP deficiency in humans causes an X-linked lymphoproliferative syndrome. Nature. 2006;444:110-4.

7. Hafezi N, Zaki-Dizaji M, Nirouei M, Asadi G, Sharifinejad N, Jamee M, et al. Clinical, immunological, and genetic features in 780 patients with autoimmune lymphoproliferative syndrome (ALPS) and ALPS-like diseases: A systematic review. Pediatr Allergy Immunol. 2021 May 8. doi: 10.1111/pai.13535..

8. Chandrakasan S, Chandra S, Davila Saldana BJ, Torgerson TR, Buchbinder D. Primary immune regulatory disorders for the pediatric hematologist and oncologist: A case-based review. Pediatr Blood Cancer. 2019;66:e27619.

9. Calabrò ML, Sarid R. Human Herpesvirus 8 and Lymphoproliferative Disorders. Mediterr J Hematol Infect Dis. 2018;10:e2018061.

10. Oliveira JB, Bleesing JJ, Dianzani U, Fleisher TA, Jaffe ES, Lenardo MJ, et al. Revised diagnostic criteria and classification for the autoimmune lymphoproliferative syndrome (ALPS): report from the $2009 \mathrm{NIH}$ International Workshop. Blood. 2010;116:e35-40.

11. Chandrakasan S, Chandra S, Davila Saldana BJ, Torgerson TR, Buchbinder D. Primary immune regulatory disorders for the pediatric hematologist and oncologist: A case-based review. Pediatr Blood Cancer. 2019;66:e27619.

12. Lee WI, Kuo ML, Huang JL, Lin SJ, Wu CJ. Distribution and clinical aspects of primary immunodeficiencies in a Taiwan pediatric tertiary hospital during a 20-year period. J Clin Immunol. 2005; 25:162-73.

13. Lee WI, Torgerson TR, Schumacher MJ, Yel L, Zhu Q, Ochs HD. Molecular analysis of a large cohort of patients with the hyper immunoglobulin M (IgM) syndrome. Blood. 2005; 105:1881-90.

14. Lee WI, Huang JL, Kuo ML, Lin SJ, Chen LC, Chen MT, et al. Analysis of genetic defects in patients with the common variable immunodeficiency phenotype in a single Taiwanese tertiary care hospital. Ann Allergy Asthma Immunol. 2007; 99:433-42.

15. Lee WI, Huang JL, Lin SJ, Yeh KW, Chen LC, Ou LS, et al. Lower T Regulatory and Th17 Cell Populations Predicted byRT-PCR-Amplified FOXP3 and RORYt Genes Are Not Rare in Patients With Primary Immunodeficiency Diseases. Front Immunol. 2020;11:1111.

16. Appay V, et al. Phenotype and function of human T lymphocyte subsets: consensus and issues. Cytometry A 2008;73:975-983.

17. Brenchley JM, Karandikar NJ, Betts MR, Ambrozak DR, Hill BJ, Crotty LE, et al. Expression of CD 57 defines replicative senescence and antigeninduced apoptotic death of CD8+ T cells. Blood 2003;101:2711-2720.

18. Focosi D, Bestagno M, Burrone O, Petrini M. CD57+ T lymphocytes and functional immune deficiency. J Leukoc Biol 2010; 87:107-116.

19. Koch S, Larbi A, Ozcelik D, Solana R, Gouttefangeas C, Attig S, et al. Cytomegalovirus infection: a driving force in human T cell immunosenescence. Ann N Y Acad Sci 2007;1114:23-35.

20. Coulter TI, Cant AJ. The Treatment of Activated PI3Kס Syndrome. Front Immunol. 2018 Sep 7;9:2043. doi: 10.3389/fimmu.2018.02043. PMID: 30245694; PMCID: PMC6137162.

21. Kim CH, Rott LS, Clark-Lewis I, Campbell DJ, Wu L, Butcher EC. Subspecialization of CXCR5+ T cells: B helper activity is focused in a germinal centerlocalized subset of CXCR5+ T cells. J Exp Med 2001;193:1373-1381.

22. Bryant VL, Ma CS, Avery DT, Li Y, Good KL, Corcoran LM, et al. Cytokine-mediated regulation of human B cell differentiation into Ig-secreting cells: predominant role of IL-21 produced by CXCR5+ T follicular helper cells. J Immunol 2007;179:8180-8190.

23. Sanz I, Wei C. Challenges and Opportunities for Consistent Classification of Human B Cell and Plasma Cell Populations. Front Immunol. $2019 ; 10: 2458$.

24. Thorarinsdottir K, Camponeschi A, Cavallini N, Grimsholm O, Jacobsson L, Gjertsson I, et al. CD21(-/low) B cells in human blood are memory cells. Clin Exp Immunol. 2016;185:252-62.

25. Moura RA, Quaresma C, Vieira AR, Gonçalves MJ, Polido-Pereira J, Romão VC, et al. B-cell phenotype and IgD-CD27- memory B cells are affected by TNFinhibitors and tocilizumab treatment in rheumatoid arthritis. PLoS One. 2017;12:e0182927.

26. Browne SK, Zaman R, Sampaio EP, Jutivorakool K, Rosen LB, Ding L, et al. Anti-CD20 (rituximab) therapy for anti-IFN-y autoantibody-associated nontuberculous mycobacterial infection. Blood. 2012;119(17):3933-9.

27. Chan AY, Leiding JW, Liu X, Logan BR, Burroughs LM, Allenspach EJ, et al. Hematopoietic Cell Transplantation in Patients With Primary Immune Regulatory Disorders (PIRD): A Primary Immune Deficiency Treatment Consortium (PIDTC) Survey. Front Immunol. 2020 Feb 21;11:239. doi: 10.3389/fimmu.2020.00239. PMID: 32153572; PMCID: PMC7046837.

\section{Figures}


Figure 1
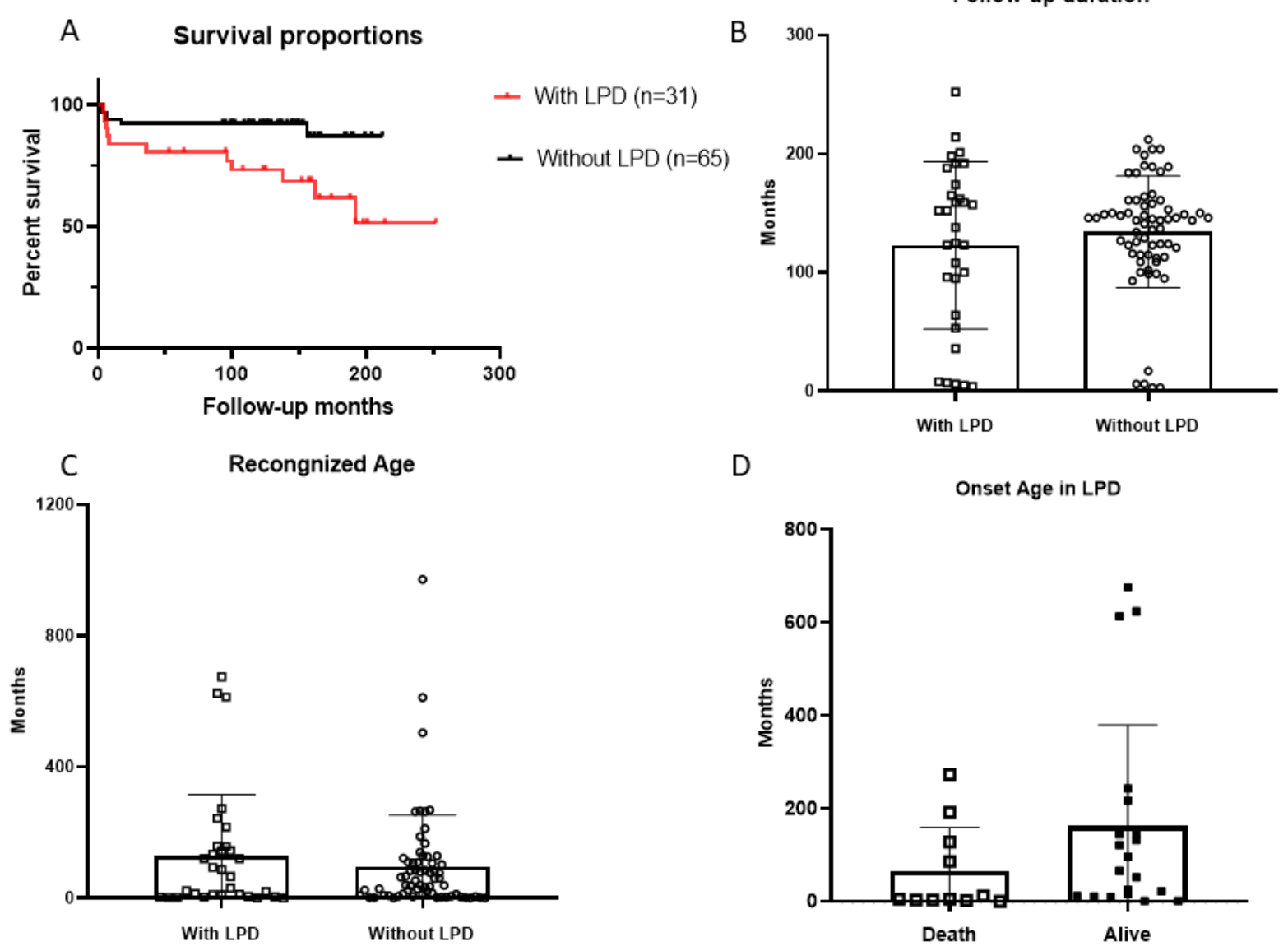

D

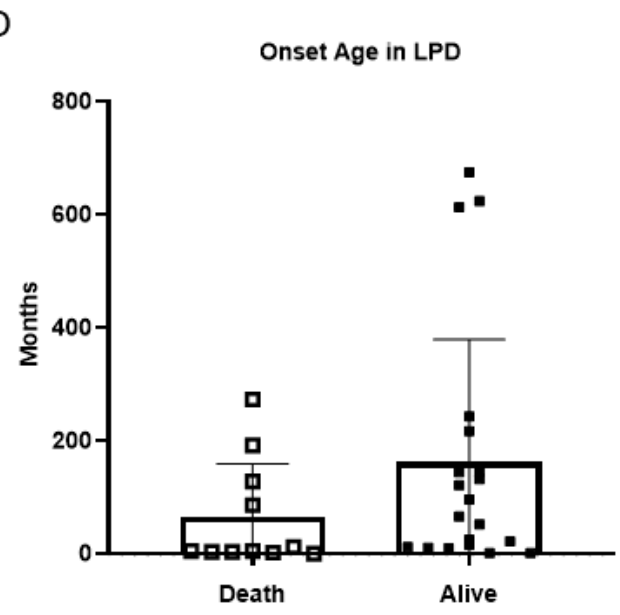

Figure 1

The PID patients with the LPD phenotype had a significantly higher mortality rate $(p=0.0061$, log-rank test; $p=0.0124$, Wilcoxon test) compared to those without the LPD phenotype (A) during a similar follow-up period (median 138 vs 144 months $p=0.3470$ ) (B) and age at recognition (median 66 vs 40 months, $\mathrm{p}=0.3672$ ) (C). However, the age at onset of the LPD phenotype was not significantly different (median 81 vs median 5 months, $p=0.1730$ ) in those who survived and died (D). 
Figure 2

\section{Healthy Control}

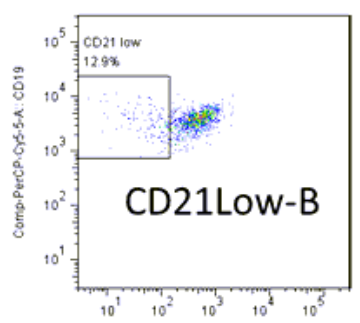

COmpifTC:A $C 021$

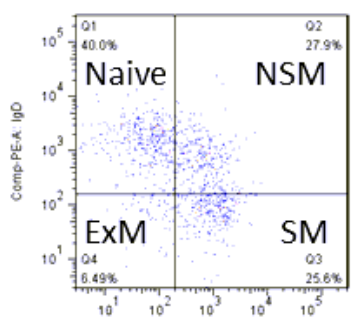

Comp.APC-A:CD27

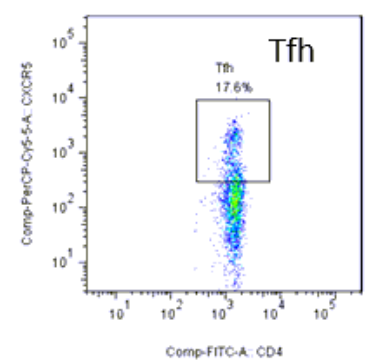

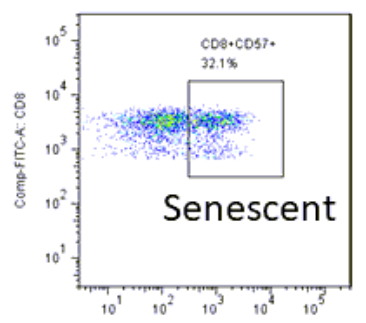

COMOPE. $\cdot$ - $\cos 7$

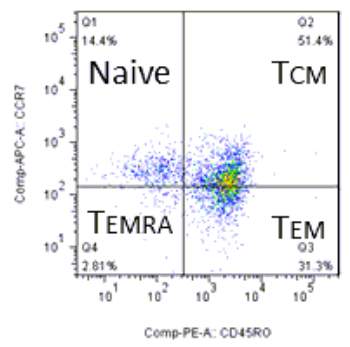

Comp-PE.A. COASRO

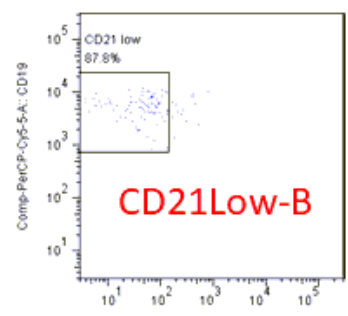

Comperacen co21

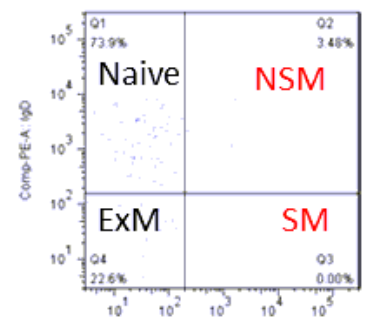

Comp-APCA:CD27

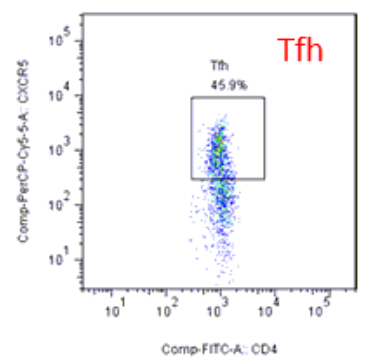

Patient (P728)
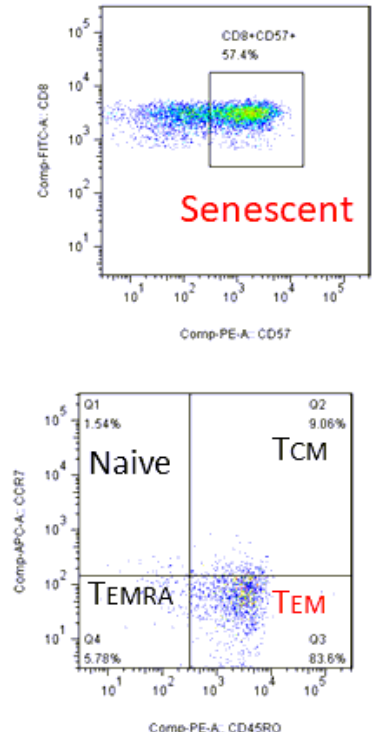

COMPPE-A. CD45PO

Figure 2

In immunophenotyping analysis, patient P728 with a PIK3R1 mutation had decreased memory B (switched IgD+CD27+ and non-switched IgD-CD27+memory CD19 cells; $3.5 \%$ vs $53.5 \%$ in the second lane) but higher CD4+ effector memory T (CD45RO+CCR7- CD4 cells, $83.6 \%$ vs $21.3 \%$ in the second lane) and CD21low B (87.8\% vs $12.9 \%$ in the first lane) cell components, especially higher Tfh ( $45.9 \%$ vs $17.6 \%$ in the third lane) and senescent CD8+CD57+ components ( $57.4 \%$ vs $32.1 \%$ in the first lane) compared with the healthy control (B). 
Figure 3
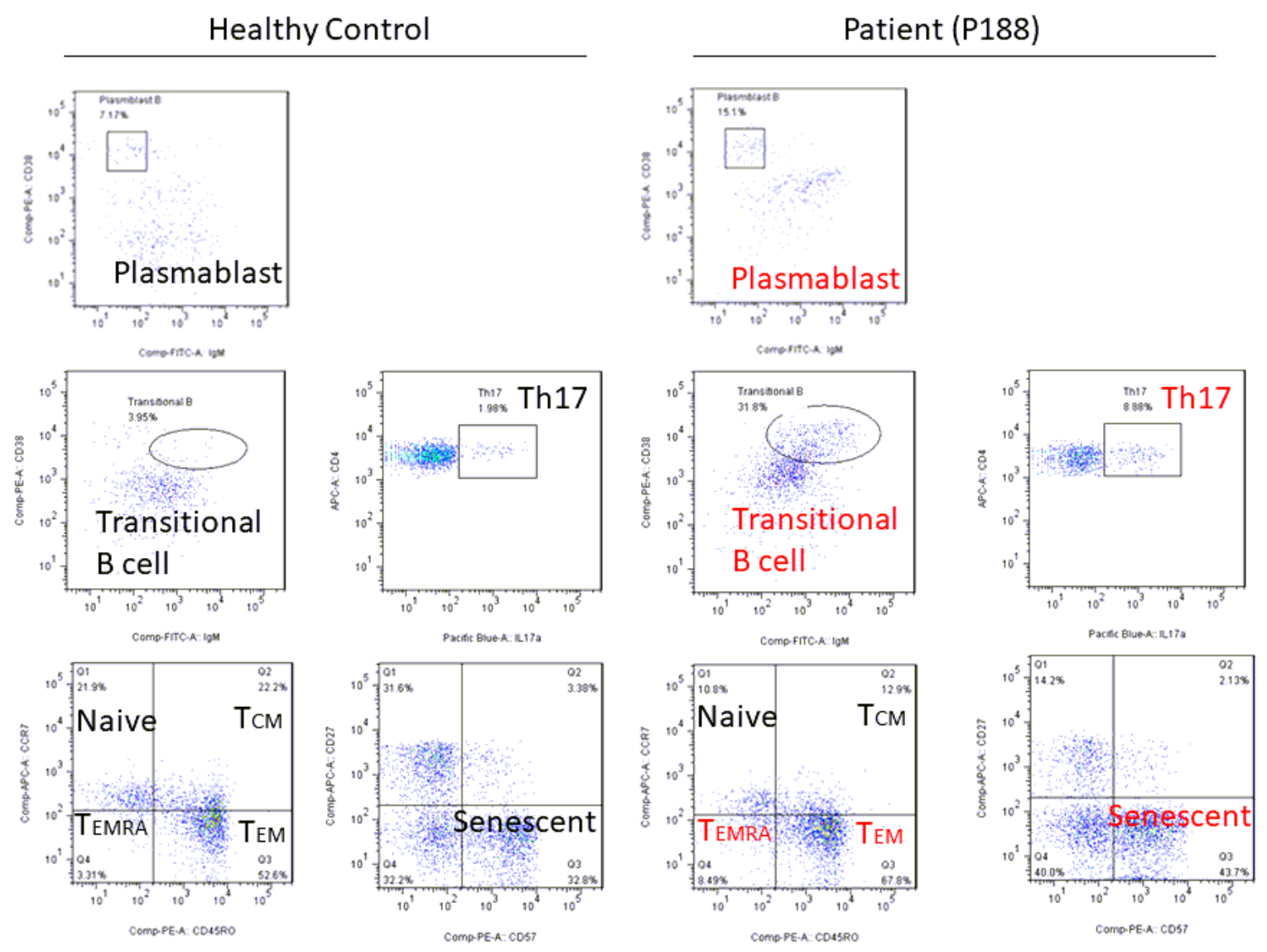

Figure 3

Patient P188 with autoantibodies to IFN-y had higher components of transitional B (CD38++lgM++ 31.8\% vs $3.9 \%$ in the second lane), plasmablast B (CD38++lgM- $15.1 \%$ vs $7.2 \%$ in the first lane), effector CD 4 memory (CD45RO+CCR7- CD 4 cells; $67.8 \%$ vs $52.5 \%$ in the third lane), TEMRA (CD45RO-CCR7- CD4 cells; $8.5 \%$ vs $3.3 \%$ in the third lane), senescent CD $8+C D 57+(43.7 \%$ vs $32.8 \%$ in the third lane) and the highest Th17 components $(8.8 \%$ vs $2.0 \%$ in the second lane) compared to the healthy control. 


\section{Figure 4}
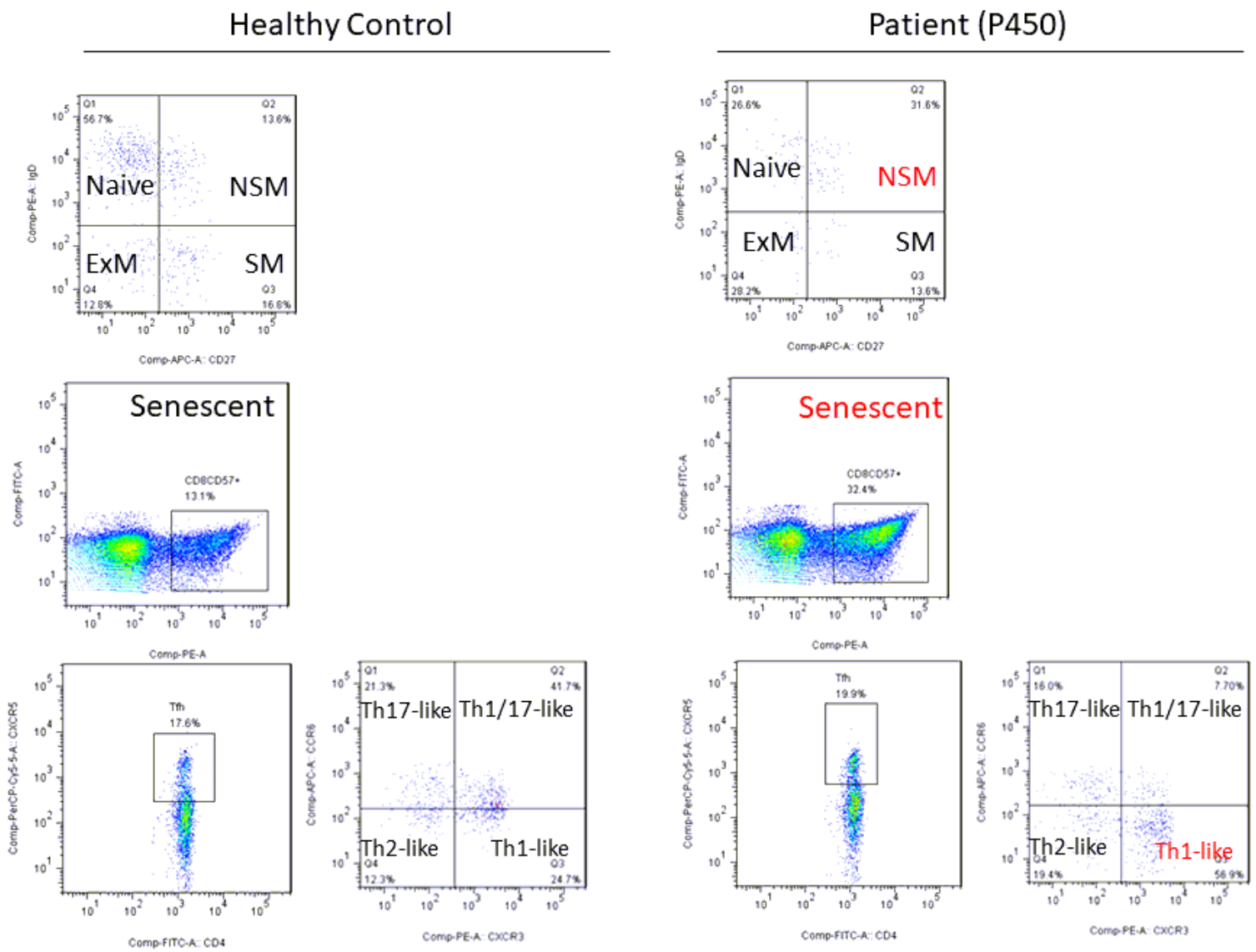

\section{Figure 4}

The X-linked granulomatous diseases (XL-CGD) patient P450 had higher non-class-switched memory B (IgD+CD27+memory $31.6 \%$ vs $13.6 \%$ in the first lane) and senescent CD8+CD57+ components (32.4\% vs 13.1 in the second lane). However, the normal Tfh components (CD4+CXCR5+; $30.8 \%$ vs $23.9 \%$ in the third lane) were skewed to Th1 (CXCR3+CCR6-; $56.9 \%$ vs $24.7 \%$ in the third lane) and could elicit a robust IFN-y response to possibly induce a cytokine storm consequently driving the HLH crisis. 
Figure 5

A

Healthy Control

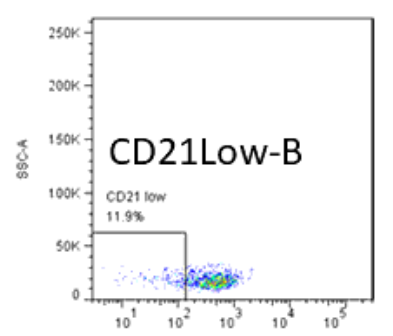

Patient (P682)
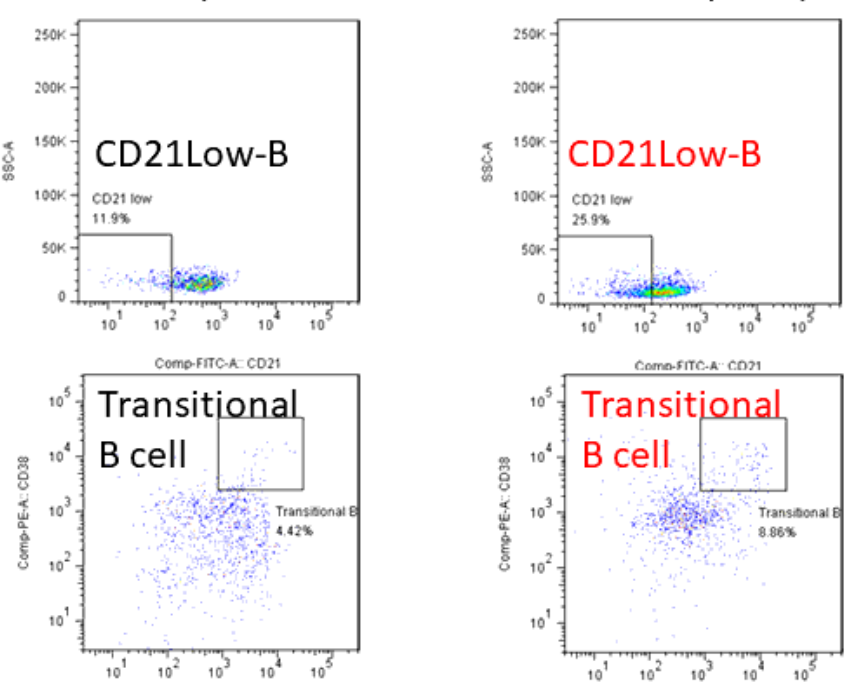

Camas SITCA C. Con

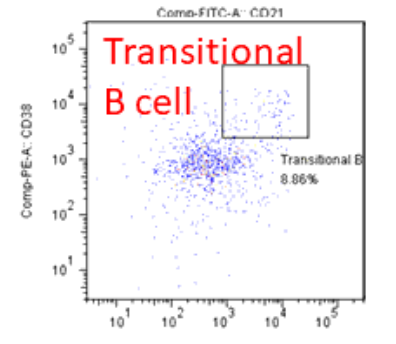

Comp-firche: igk

Comp-Fitcicilon

B
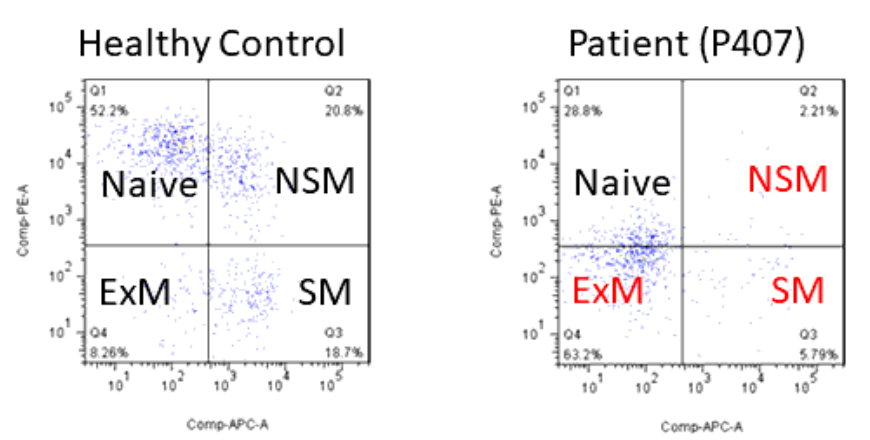

Figure 5

The XIAP patient (P682) had higher CD21-low (25.9\% vs 11.9\%) and transitional B components (8.9\% vs 4.4\%) under CD19 gating (A). The IPEX patient (P407) had higher exhausted memory (IgD-CD27- or IgD-IgM-; 63.2\% vs 8.3\%) double negative cell components under CD19 gating (B).

\section{Supplementary Files}

This is a list of supplementary files associated with this preprint. Click to download.

- SupplementalTable1.docx

- Supp.Fig1andEng.Revised.docx 